Gut, 1981, 22, 827-835

\title{
Study of acute localised inflammation of the gastrointestinal tract: the effluent lymph
}

\author{
H W STEER* \\ From the Nuffield Department of Surgery, University of Oxford, John Radcliffe Hospital, Oxford
}

SUMMARY The effect of localised acute inflammation, produced by a small intestinal anastomosis on the effluent lymph of the gastrointestinal tract and on the efferent lymph of the mesenteric lymph glands has been studied in rats. There is a progressive increase in the output of lymph from the gastrointestinal tract in rats with an intact anastomosis, but a decreased output in animals with a disrupted anastomosis causing either generalised peritonitis or a localised paraanastomotic abscess. The total white cell output is increased on the second day after constructing an intact intestinal anastomosis and this increase is principally due to neutrophil polymorphonuclear leucocytes. The neutrophil polymorphonuclear leucocyte response is prolonged, but has returned to normal values at four weeks. Although the output of cells of the mononuclear phagocytic series which are esterase positive is increased it is not statistically significant. An intact anastomosis does not produce any alteration in the lymphocyte output. The neutrophil polymorphonuclear leucocyte response to an intestinal anastomosis is decreased by a factor of two and the non-lymphocytic, non-specific esterase positive cell response is decreased by a factor of six by the mesenteric lymph glands which may be functioning in a 'filtering' capacity dealing with agents originating at the anastomosis and noxious to the body.

The cellular changes associated with acute inflammation have been studied at numerous sites using various causative agents. ${ }^{1}$ The inflammatory response of the gastrointestinal tract has yet to be critically examined. If the gastrointestinal mucosal continuity is broken either deliberately or by a disease process the body is exposed to the numerous bacteria present in the lumen and mounts an appropriate inflammatory response.

An intestinal anastomosis produces a localised discontinuity in the mucosa of the intestine. This is a frequent procedure carried out during intestinal surgery in humans. This break in mucosal continuity results in an inflammatory response which, if successful, enables mucosal continuity to be re-established. Two factors are important in the re-establishment of mucosal continuity, the inflammatory response and epithelialisation of the luminal surface of the anastomosis. A study of this inflammatory response

*Present address: Southampton General Hospital, Tremona Road. Southampton.

Received for publication I April 1981 may lead to a greater understanding of the factors responsible for a successful outcome to intestinal anastomoses and a greater knowledge of the changes occurring during acute localised inflammation of the gastrointestinal tract.

The presence of inflammatory cells and oedema are two of the characteristics of acute inflammation. The tissue plasma proteins and the cellular debris at the inflammatory focus cannot be absorbed directly into the blood vessels. ${ }^{2}$ Similarly, cells at an inflammatory focus cannot directly enter the blood vessels. ${ }^{34}$ The tissue plasma proteins and cells must enter the lymphatic channels before gaining access to the systemic circulation. From a localised inflammatory focus of the gastrointestinal tract this involves entry of tissue plasma proteins and cells into the lymphatic channels either directly or via the peritoneal cavity. It would therefore seem logical that the lymphatic effluent from the gastrointestinal tract should be examined in any study of the cellular effluent from an inflammatory focus which is based on the gastrointestinal tract. A histological examina827 
morphological indication of events occurring at the time of taking the sample.

The purpose of the present study is to examine the changes in the effluent lymph of the gastrointestinal tract produced by local inflammation using the model used in a previous study of this lymph. ${ }^{5}$

\section{Methods}

Inbred female rats (Lewis strain) were used after being housed for at least four weeks in a conventional animal house after removal from a specific pathogen-free environment. Either normal rats or rats that had, six weeks earlier, had their mesenteric lymph glands removed (MLNX) were used in the study. The mesenteric lymph glands in the rats are found at three main sites; a group located near the caecum, a chain of glands along the course of the superior mesenteric vessels, and a group around the portal vein. ${ }^{6}$ These lymph glands were carefully avulsed with minimal damage to the surrounding tissue. After removal of the mesenteric lymph glands in the rats, the lymph flow from the gastrointestinal tract into the thoracic duct was reestablished by six weeks so that an analysis of the thoracic duct lymph enabled a direct study to be made of the effluent lymph from the gastrointestinal tract. $^{5}$

The localised acute inflammation of the gastrointestinal tract was produced by a small intestinal anastomosis. This was constructed in an everting end-to-end manner approximately $6-10 \mathrm{~cm}$ from

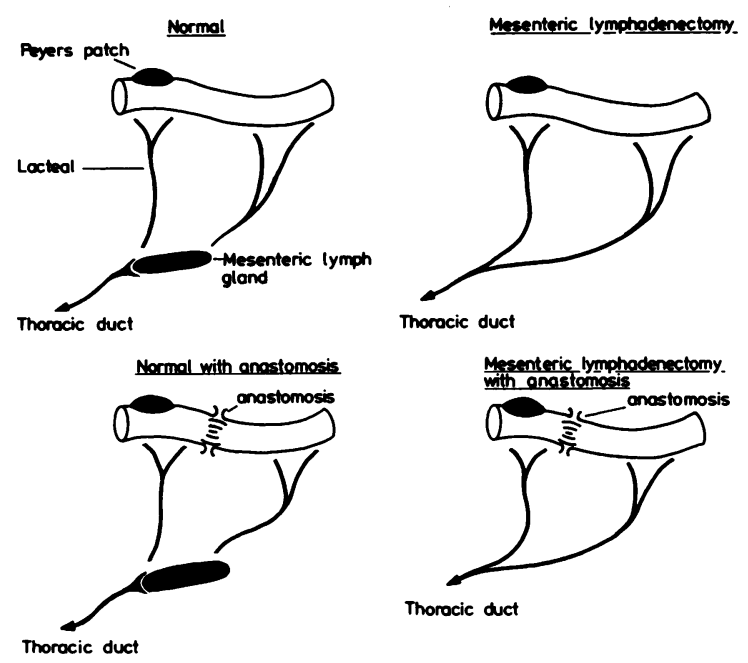

Fig. 1 Diagrammatic representation of the modifications of the experimental small intestinal rat model. the ileocaecal junction using interrupted 0000000 silk sutures (Ethicon Ltd, Edinburgh).

Thoracic duct lymph analyses and histological examinations of the anastomosis were performed in a number of modifications of the experimental model (Fig. 1). Rats with intact or disrupted small intestinal anastomoses were examined. The disruption of the anastomgsis caused either a paraanastomotic abscess or peritonitis. All anastomoses were carried out using the previous technique, but some spontaneously disrupted and these were detected at necropsy.

The thoracic duct was cannulated under ether anaesthesia. ${ }^{7}$ All those animals whose thoracic duct lymph had been drained, also had a cannula inserted into the inferior vena cava via the left femoral vein. The rats received a continuous intravenous infusion of $0.9 \% \mathrm{Na} \mathrm{Cl}$ containing 1 unit heparin $/ \mathrm{ml}$ at a rate of $3 \mathrm{ml} / \mathrm{h}$. The rats were allowed unlimited access to food and water.

Overnight collections of the thoracic duct lymph were obtained; the lymph being collected in siliconised conical flàsks containing $5 \mathrm{ml}$ Dulbecco A plus B (DAB, Oxoid Ltd) solution with 20 units heparin $/ \mathrm{ml}$ at $0^{\circ} \mathrm{C}$. The thoracic duct lymph was collected for five days except in those animals with a disrupted anastomosis. These animals could be distinguished from those with an intact anastomosis on the second day after surgery because they stopped eating and their lymph became strawcoloured as opposed to the opalescent colour of normal gastrointestinal lymph. Such animals with a disrupted anastomosis were killed on the third day.

The collections of overnight thoracic duct lymph were measured and the time of the collection recorded. The first collection was started approximately six to nine hours after setting up the experimental system. The lymph was centrifuged at $1000 \mathrm{rpm}$ for 10 minutes at $4^{\circ} \mathrm{C}$ and the supernatant removed. The cells were then washed twice with $\mathrm{DAB} / 10 \%$ fetal calf serum using siliconised glassware. The cellular suspension was again centrifuged at $1000 \mathrm{rpm}$ for 10 minutes at $4^{\circ} \mathrm{C}$ and the supernatant removed. The cells were finally re-suspended in $10 \mathrm{ml} \mathrm{DAB} / 10 \%$ fetal calf serum so that the cellular concentration could be determined with the improved Neubauer haemacytometer. Cytocentrifuge preparations were fixed in either formalin vapour for one minute for non-specific esterase staining or citrate buffered acetone solution (Sigma London Chemical Company, Poole, UK) for 30 seconds for acid phosphatase staining. The nonspecific esterase was identified using $\alpha$ naphthyl butyrate as substrate at $\mathrm{pH} 6 \cdot 0^{8}$ and counterstained with Giemsa's stain. The acid phosphatase was localised using naphthol AS-BI phosphate as 
substrate at pH 5.2 (Sigma London Chemical Company, Poole, UK) and counterstained with acid haematoxylin. The histochemical techniques were used to identify cells of the mononuclear phagocytic system. The morphological characteristics of the different cell types counted were identical with those used in previous investigations. ${ }^{9}$

A phagocytic assay was performed incubating the lymph cells in suspension with sensitised sheep red blood cells and complement for 40 minutes at $37^{\circ} \mathrm{C}$. The non-phagocytosed sheep red blood cells were removed with Tris ammonium chloride before making cytocentrifuge preparations for non-specific esterase or acid phosphatase staining.

After completing the thoracic duct lymph collection, the site of the intestinal anastomosis was excised. This portion of intestine was fixed in formalsublimate for 12 to 36 hours. In addition, small intestinal anastomoses were performed in seven normal rats. After five days (without cannulation of the thoracic duct) the anastomosis was removed and fixed in formal-sublimate. The fixed specimens were dehydrated in a graded series of ethanol solutions, cleared in chloroform and embedded in paraffin wax. Tissue sections $(5 \mu \mathrm{m})$ were cut and stained with haematoxylin and eosin.

All statistical analyses were carried out using Student's unpaired $t$ test.

\section{Results}

LYMPHATIC RESPONSE TO INTACT INTESTINAL ANASTOMOSIS

The output of lymph from the gastrointestinal tract of rats with an intact anastomosis continues to increase during the five days of lymph collection (Fig. 2). This output reached a maximum of $6.9 \mathrm{ml} / \mathrm{h}$ on the fifth day, a level that was considerably greater than the output of $3.3 \mathrm{ml} / \mathrm{h}$ of the control MLNX rats lacking an anastomosis.

After a small intestinal anastomosis, only on the second day is there a significant increase $(\mathrm{P}<0 \cdot 05)$ in the total white cell output in the effluent lymph from the gastrointestinal tract (Table 1). If the subpopulations of these cells are examined, the most notable feature was the change in the neutrophil polymorphonuclear leucocyte (PNL) output (Table 2). In control (MLNX) rats there were few neutrophil polymorphonuclear leucocytes in the effluent lymph, but, after small intestinal anastomosis, there was a significant increase in the number of these cells on the second $(\mathrm{P}<0 \cdot 01)$, third $(\mathrm{P}<0.05)$, and fourth $(P<0.05)$ days. The maximum output of polymorphonuclear leucocytes was achieved on day two.

The output of non-lymphocytic, non-specific esterase (NSE) positive cells is increased on day two after a small intestinal anastomosis in MLNX rats (Table 3), but failed to achieve statistical significance. One functional analysis of the cells which has been examined in this study is the phagocytosis of sensitised sheep red blood cells (SSRBC) (Table 4). This analysis revealed an increased output of phagocytic cells on days two, three, four, and five after intestinal anastomosis, but the increase was significant only on day four $(\mathrm{P}<0 \cdot 05)$. Two cell types formed this phagocytic population, the nonlymphocytic non-specific esterase cells and the polymorphonuclear leucocytes. The non-lymphocytic non-specific esterase positive cells which are

Table 1 Number of white cells in thoracic duct lymph $\times 10^{-}$per hour (mean + standard error of mean)

\begin{tabular}{|c|c|c|c|c|c|c|c|c|c|c|}
\hline \multirow{2}{*}{\multicolumn{3}{|c|}{$\begin{array}{l}\text { Experiment } \\
\text { no. }\end{array}$}} & & & \multirow{2}{*}{$\begin{array}{l}\text { Rats } \\
\text { (no.) }\end{array}$} & \multicolumn{5}{|c|}{ Day of thoracic duct lymph drainage } \\
\hline & & & & & & 1 & 2 & 3 & 4 & 5 \\
\hline 1 & \multirow{2}{*}{\multicolumn{2}{|c|}{$\begin{array}{l}\text { Normal } \\
\text { Mesenteric } \\
\text { lymphadenectomy }\end{array}$}} & \multirow{2}{*}{\multicolumn{2}{|c|}{$\begin{array}{l}\text { Immediate intact anastomosis } \\
\text { Control, no anastomosis }\end{array}$}} & 5 & $2 \cdot 12=0 \cdot 4$ & $1.63: 0.4$ & $0.96 \div 0.2$ & $0.52=0.1$ & $0.45=0.2$ \\
\hline 2 & & & & & 7 & $1 \cdot 49=0 \cdot 2$ & $0.90=0 \cdot 1$ & $0.65=0.1$ & $0.57=0.1$ & $0 \cdot 34-0 \cdot 1$ \\
\hline 3 & \multicolumn{2}{|c|}{$\begin{array}{l}\text { Mesenteric } \\
\text { lymphadenectomy }\end{array}$} & \multicolumn{2}{|c|}{ Immediate intact anastomosis } & 8 & $1 \cdot 45=0 \cdot 3$ & $1 \cdot 26=0 \cdot 2$ & $0.94=0.2$ & $0.47 \div 0.1$ & $0 \cdot 35 \div 0 \cdot 1$ \\
\hline 4 & \multicolumn{2}{|c|}{$\begin{array}{l}\text { Mesenteric } \\
\text { lymphadenectomy }\end{array}$} & \multicolumn{2}{|c|}{$\begin{array}{l}\text { Immediate disrupted } \\
\text { anastomosis }\end{array}$} & 6 & $1 \cdot 17=0 \cdot 2$ & $0.74 \pm 0.2$ & $0 \cdot 20 \pm 0 \cdot 1$ & - & - \\
\hline 5 & \multicolumn{2}{|c|}{$\begin{array}{l}\text { Mesenteric } \\
\text { lymphadenectomy }\end{array}$} & \multicolumn{2}{|c|}{ One week intact anastomosis } & 5 & $0.97 \pm 0.2$ & $0.66=0 \cdot 1$ & $0 \cdot 71=0 \cdot 1$ & $0.44 \pm 0 \cdot 1$ & $0 \cdot 28 \pm 0 \cdot 1$ \\
\hline 6 & \multicolumn{2}{|c|}{$\begin{array}{l}\text { Mesenteric } \\
\text { lymphadenectomy }\end{array}$} & \multicolumn{2}{|c|}{ Four week intact anastomiosis } & 6 & $1 \cdot 55 \div 0 \cdot 25$ & $0 \cdot 85 \div 0 \cdot 1$ & $0 \cdot 55=0 \cdot 1$ & $0 \cdot 40=0.1$ & $0 \cdot 31=0 \cdot 1$ \\
\hline \multicolumn{11}{|c|}{ Significant statistical analyses: } \\
\hline \multicolumn{2}{|c|}{ Experiment no. } & \multicolumn{2}{|c|}{ Day of collection } & Probability & & \multicolumn{2}{|c|}{ Experiment no. } & \multicolumn{2}{|c|}{ Day of collection } & Probability \\
\hline \multicolumn{2}{|c|}{$\begin{array}{l}1 \text { compared with } 2 \\
1 \text { compared with } 4 \\
1 \text { compared with } 4 \\
1 \text { compared with } 5 \\
1 \text { compared with } 6 \\
1 \text { compared with } 6\end{array}$} & $\begin{array}{l}2 \\
2 \\
3 \\
2 \\
2 \\
3\end{array}$ & & $\begin{array}{l}<0.05 \\
<0.01 \\
<0.01 \\
<0.05 \\
<0.05 \\
<0.05\end{array}$ & & \multicolumn{2}{|c|}{$\begin{array}{l}2 \text { compared with } 3 \\
2 \text { compared with } 4 \\
3 \text { compared with } 4 \\
4 \text { compared with } 5 \\
4 \text { compared with } 6\end{array}$} & $\begin{array}{l}2 \\
3 \\
3 \\
3 \\
3\end{array}$ & & $\begin{array}{l}<0.05 \\
<0.01 \\
<0.01 \\
<0.01 \\
<0.02\end{array}$ \\
\hline
\end{tabular}


phagocytic are weakly staining for that enzyme: the strongly positive non-specific esterase cells tended to be non-phagocytic. The majority (greater than $99 \%$ ) of the phagocytic non-lymphocytic nonspecific esterase positive cells contained tartrate labile acid phosphatase, whereas the non-phagocytic cells which stained intensely for non-specific esterase

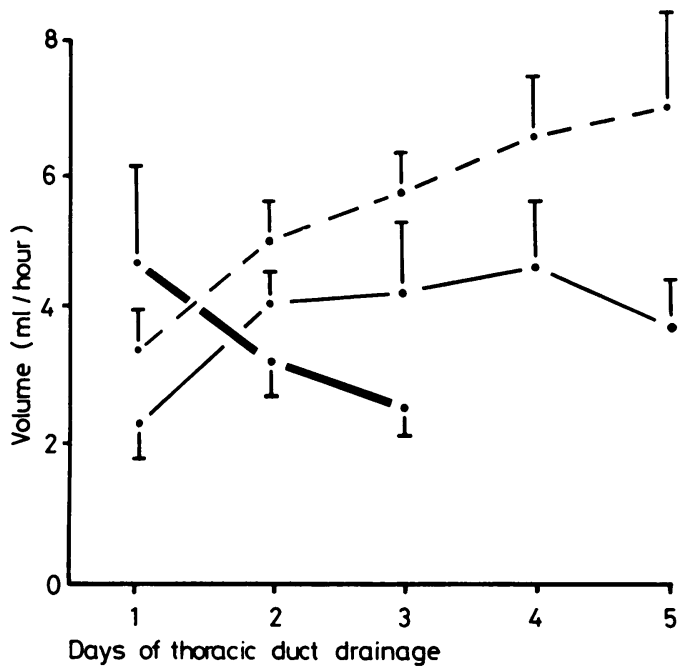

Fig. 2 The volume of lymph obtained after thoracic duct cannulation (mean \pm standard error of the mean). - Control mesenteric lymphadenectomised rats. --- Mesenteric lymphadenectomised rats immediately after constructing an intact small intestinal anastomosis. - Mesenteric lymphadenectomised rats immediately after constructing a disrupted small intestinal anastomosis. contained tartrate stable acid phosphatase. Not all the polymorphonuclear leucocytes are phagocytic. Both the phagocytic and non-phagocytic polymorphonuclear leucocytes contained tartrate labile acid phosphatase.

There is no difference in the total lymphocyte output in control MLNX rats compared with MLNX rats immediately after small intestinal anastomosis (Table 5).

The preceding results were obtained from rats immediately after constructing a small intestinal anastomosis, but how long do these changes persist? In those MLNX rats which had had a small intestinal anastomosis for one week the total white cell output on the first day of thoracic duct drainage was low (Table 1), but the cellular output on the third to the fifth days was similar to that obtained from the other groups of MLNX rats. On day two the output is significantly decreased when compared with those rats whose thoracic ducts were cannulated at the time of constructing the anastomosis $(\mathrm{P}<0 \cdot 02)$. The polymorphonuclear leucocyte output was raised in those rats one week after small intestinal anastomosis being significantly increased on day two $(\mathrm{P}<0.001)$, day three $(\mathrm{P}<0.05)$, and day four $(\mathrm{P}<0 \cdot 05)$ of thoracic duct lymph drainage (Table 2$)$. The output of non-lymphocytic non-specific esterase positive cells was similar to that observed in the control MLNX rats (Table 3). The lymphocyte output of the gastrointestinal tract in these rats which had had an intestinal anastomosis for one week was significantly less on the second day $(\mathrm{P}<0.05)$ than either normal or MLNX rats immediately after the construction of an intact anastomosis.

Table 2 Number of neutrophil polymorphonuclear leucocytes in thoracic duct lymph $\times 10^{-5}$ per hour (mean \pm standard error of mean)

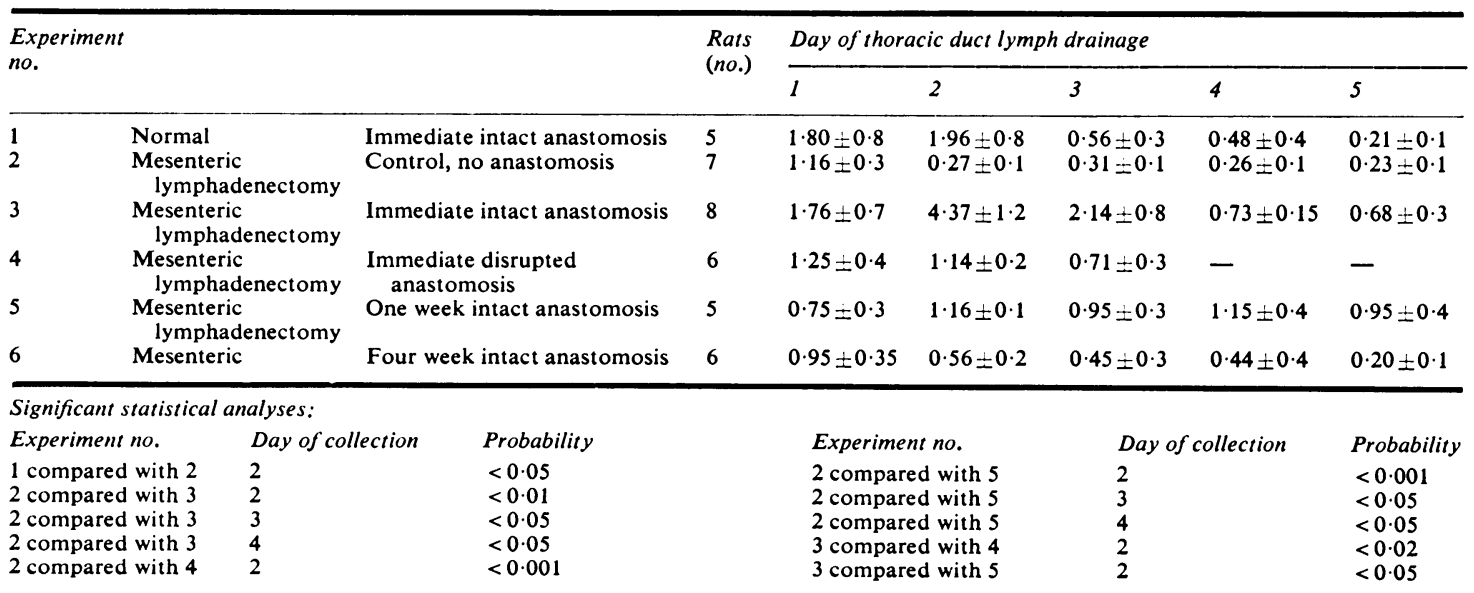


Some MLNX rats had a small intestinal anastomosis constructed four weeks before thoracic duct drainage. The total cell output (Table 1), the polymorphonuclear leucocyte output (Table 2), the non-lymphocytic non-specific esterase positive cell output (Table 3), and the total lymphocyte output (Table 5) in the effluent lymph of the gastrointestinal tract in these rats were similar to that of control MLNX rats.

Granulation tissue develops across the base of the intestinal anastomosis during the first week. The granulation tissue is covered on its luminal surface by a cellular plug. The size of this cellular plug is variable among individual specimens. It does not seem to bear any relationship to the type of procedure performed on the rat, but dependent on such iactors as the orientation of the specimen and the physical damage inflicted during processing the tissue. It was therefore decided that the cellular content of the granulation tissue should be used as an indication of the dynamic process occurring at the site of the anastomosis. The number of polymorphonuclear leucocytes in the granulation tissue at the base of the anastomosis on the fifth day after construction of an intact intestinal anastomosis was similar in rats that had had thoracic duct drainage compared with undrained rats.

\section{EFFECT OF MESENTERIC LYMPH GLAND ON} CELLULAR RESPONSE TO INTACT INTESTINAL ANASTOMOSIS

The total white cell output tends to be greater on the first and second days after the construction of a small intestinal anastomosis in normal rats when

Table 3 Number of non-lymphocytic, non-specific esterase positive cells in thoracic duct lymph $\times 10^{5}$ per hour (mean \pm standard error of mean)

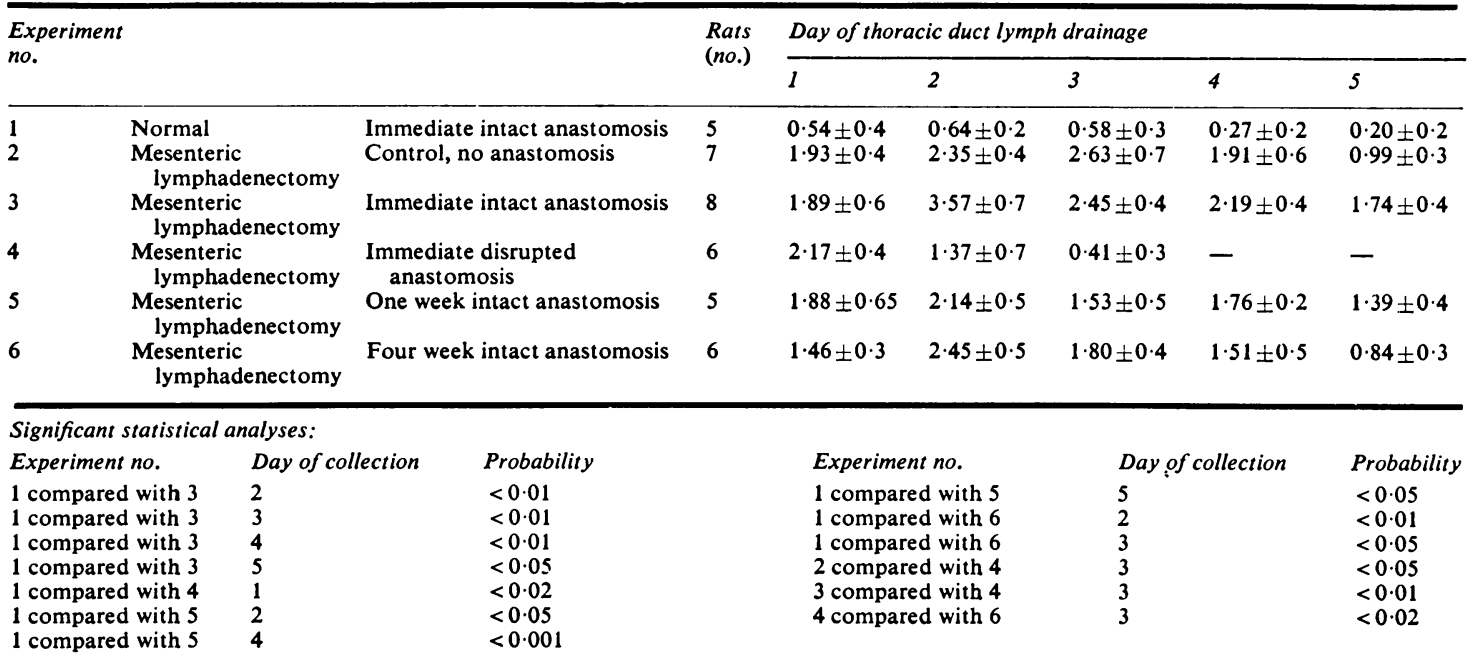

Table 4 Number of cells phagocytosing sensitised sheep red blood cells $\times 10^{-3}$ per hour (mean士standard error of mean)

\begin{tabular}{|c|c|c|c|c|c|c|c|c|}
\hline \multirow{2}{*}{$\begin{array}{l}\text { Experiment } \\
\text { no. }\end{array}$} & & & \multirow{2}{*}{$\begin{array}{l}\text { Rats } \\
\text { (no.) }\end{array}$} & \multicolumn{5}{|c|}{ Day of thoracic duct lymph drainage } \\
\hline & & & & 1 & 2 & 3 & 4 & 5 \\
\hline 2 & $\begin{array}{l}\text { Mesenteric } \\
\text { lymphadenectomy }\end{array}$ & Control, no anastomosis & 7 & $1.89 \pm 0.55$ & $0 \cdot 74=0 \cdot 10$ & $0.62 \pm 0.13$ & $0.75 \pm 0.16$ & $0.46 \pm 0.12$ \\
\hline 3 & $\begin{array}{l}\text { Mesenteric } \\
\text { lymphadectomy }\end{array}$ & Immediate intact anastomosis & 8 & $2 \cdot 07 \pm 0.49$ & $1.97 \pm 0.66$ & $2 \cdot 02 \pm 0 \cdot 71$ & $1 \cdot 35 \pm 0 \cdot 23$ & $1 \cdot 03=0 \cdot 18$ \\
\hline 4 & $\begin{array}{l}\text { Mesenteric } \\
\text { lymphadenectomy }\end{array}$ & $\begin{array}{l}\text { Immediate disrupted } \\
\text { anastomosis }\end{array}$ & 6 & $2 \cdot 01 \pm 0.83$ & $0.98 \pm 0 \cdot 15$ & $1 \cdot 14 \pm 0 \cdot 68$ & - & - \\
\hline 6 & $\begin{array}{l}\text { Mesenteric } \\
\text { lymphadenectomy }\end{array}$ & Four week intact anastomosis & 6 & $1 \cdot 07 \pm 0 \cdot 37$ & $1.01 \pm 0.29$ & $0.96 \pm 0.18$ & $0.82 \pm 0.30$ & $0.62 \pm 0.23$ \\
\hline
\end{tabular}

Significant statistical analyses:

$\begin{array}{lll}\text { Experiment no. } & \text { Day of collection } & \text { Probability } \\ 2 \text { compared with } 3 & 4 & <0.05\end{array}$ 
compared with MLNX rats (Table 1) but this increase is not statistically significant. Although the number of non-lymphocytic non-specific esterase positive cells is considerably reduced by the mesenteric lymph gland on day two $(P<0.01)$, day three $(P<0.01)$, day four $(P<0.01)$, and day five $(P<0.05)$, they are still found in thoracic duct lymph (Table 3): these cells are only rarely found in the thoracic duct lymph of normal rats lacking an intestinal anastomosis. The presence of a mesenteric lymph gland did not influence the output of polymorphonuclear lymphocytes in the thoracic duct lymph on the first day after a small intestinal anastomosis (Table 2). However, the number of polymorphonuclear lymphocytes is reduced in those rats with a mesenteric lymph gland on days two, three, four, and five, but this reduction failed to achieve statistical significance on the analysis performed.

Although the lymphocyte output of normal rats is greater on the first, second, and third days after intestinal anastomosis when compared with the MLNX rats (Table 5), the increase did not achieve statistical significance. This output in normal rats was similar to that of the other groups on the fourth and fifth days.

LYMPHATIC RESPON'SE TO DISRUPTED

INTESTINAL ANASTOMOSIS

Disruption of a small intestinal anastomosis can produce either localised inflammation (a paraanastomosis abscess) or more generalised inflammation of the peritoneal cavity (peritonitis). Both these complications have been grouped together.
The output of lymph from the gastrointestinal tract of MLNX rats with a disrupted anastomosis was lower than that from MLNX rats with an intact anastomosis (Fig. 2). This output was considerably less on day three $(2.5 \mathrm{ml} / \mathrm{h}$ compared with $5.7 \mathrm{ml} / \mathrm{h})$.

The total white cell output begins to decrease on the second day (Table 1) and on the third day the output was significantly lower $(P<0 \cdot 01)$ than that of rats with an intact anastomosis. The output of all the subpopulations of cells studied was lower in rats with a disrupted anastomosis on days two and three (Tables 2, 3, and 5), but the proportions of these cells differs from that found in rats with an intact anastomosis. The output of non-lymphocytic nonspecific esterase positive cells is significantly less on the third day $(\mathrm{P}<0 \cdot 01)$. The number of polymorphonuclear lymphocytes is decreased on the second day $(\mathrm{P}<0 \cdot 02)$.

The output of lymphocytes from these MLNX rats with a disrupted anastomosis is similar to that of animals with an intact anastomosis on the first and second days after constructing the anastomosis, but on the third day the output of lymphocytes is significantly reduced $(\mathrm{P}<0.02)$.

\section{Discussion}

VOLUME OF LYMPH FROM GASTROINTESTINAL TRACT

The output of lymph from the gastrointestinal tract in MLNX rats normally increases during the first three days of thoracic duct drainage and then decreases on the fourth and fifth days. The output from those rats with an intact anastomosis continues

Table 5 Number of lymphocytes in thoracic duct lymph $\times 10^{7}$ per hour (mean士standard error of mean)

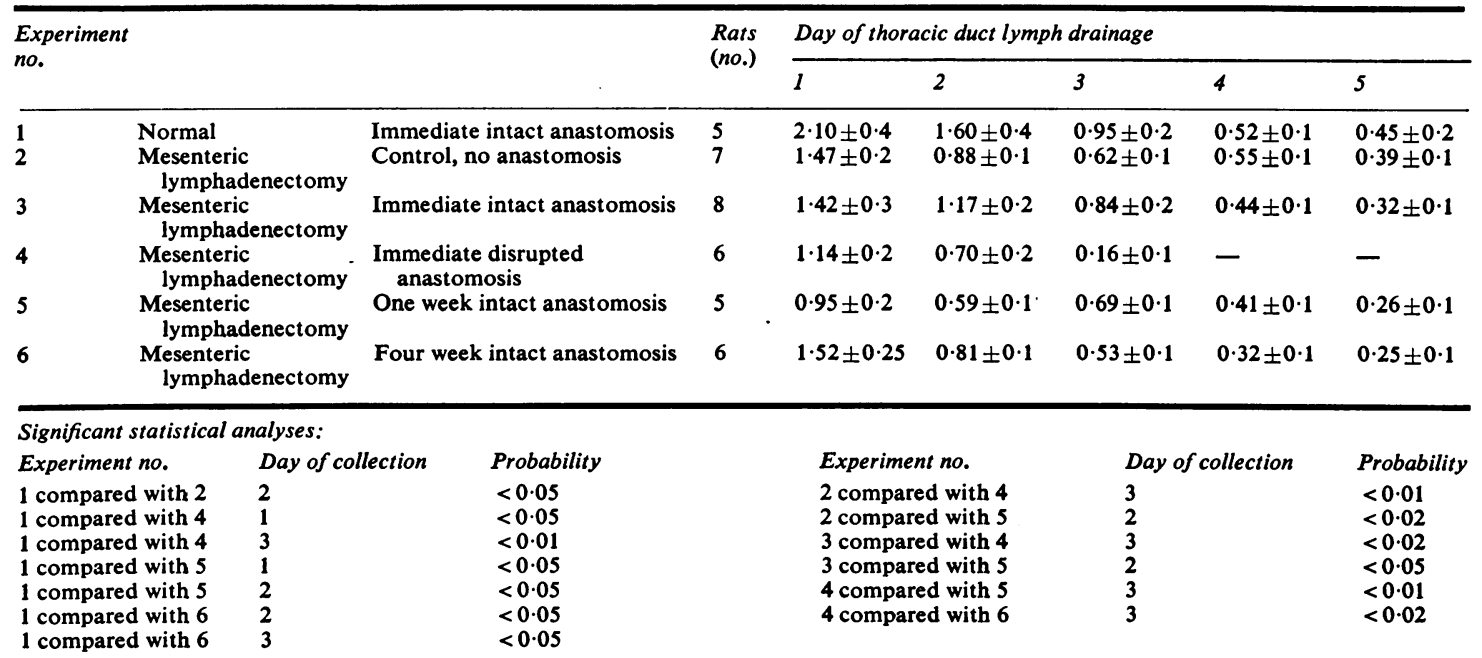


to increase for the five days of thoracic duct lymph collection so that the output on the fifth day is $6.9 \mathrm{ml} / \mathrm{h}$. This increased flow from a site of acute inflammation has been observed in the ears of the mouse ${ }^{10}$ and the guinea-pig. ${ }^{11}$

With an unsuccessful inflammatory reaction, as manifested by the disruption of the intestinal anastomosis, the lymph flow is lower on the second day and even more dramatically decreased on the third day. This may not be entirely due to a difference in oral intake as these rats seem to drink readily, but do not seem to take any food orally.

EFFECT OF INTACT INTESTINAL ANASTOMOSIS ON CELLULAR CONTENT OF INTESTINAL LYMPH The inflammatory reaction produced by an intestinal anastomosis causes changes in the cellular content of the effluent lymph from the gastrointestinal tract. The total white cell output is increased on the second day after construction of an intact small intestinal anastomosis. If the subpopulations of these cells are examined, it is found that the total lymphocyte output is unchanged, but changes are found in the polymorphonuclear lymphocytes and non-lymphocytic non-specific esterase positive cell outputs. The output of both these latter cell types is increased reaching a maximum on the second day. The increase in polymorphonuclear lymphocytes is prolonged so that the output is still high in those rats whose thoracic duct lymph collection was started on the seventh day after intestinal anastomosis. The output of polymorphonuclear lymphocytes had returned to normal levels in rats with a long-term (four week) anastomosis.

The increased output of non-lymphocytic nonspecific esterase positive cells is not prolonged and has returned to normal on the third day after intestinal anastomosis. The decrease in these cells on the third day does not appear to be due to continued loss of these cells during the first two days and their lack of adequate replacement because there is no increase found in those rats whose collection was started on the seventh day after anastomosis.

The polymorphonuclear lymphocyte response to an inflammatory focus is dependent upon the nature of the inflammatory stimulus. Agents producing mild inflammation such as plasma proteins and glycogen solutions, ${ }^{12}{ }^{13}$ new-born calf serum,,$^{14}$ and liquid paraffin ${ }^{9}$ result in an early polymorphonuclear lymphocyte increase reaching a maximum within 12 hours after stimulation and then declining rapidly. When living bacteria (Klebsiella pneumoniae) are injected intrapleurally the increase in polymorphonuclear lymphocytes continues for at least 24 hours. ${ }^{13}$ The present study involving the transgression of the gastrointestinal mucosa leads to the exposure of bacteria and food antigens. It is therefore not surprising that the polymorphonuclear lymphocyte response is prolonged.

Interestingly the non-lymphocytic non-specific esterase positive cell response is of only short duration. This would seem to be intermediate between the results observed for mild and severe inflammatory stimuli. With mild inflammatory stimulants there is an increase in the mononuclear cell response which occurs later than polymorphonuclear response and is also prolonged. ${ }^{912}{ }^{13}{ }^{15}$ However, with severe inflammatory stimulation (Klebsiella pneumoniae intrapleurally) there was no mononuclear cell response within the first 24 hours. ${ }^{13}$ It may be that there would have been a mononuclear response generated in the latter group of animals after the 24 hour period of study. The present investigation examines lymph draining from a source of inflammation. If the migration of nonlymphocytic non-specific esterase positive cells to the inflammatory site is increased for a prolonged period of time these cells are either being 'trapped' at the inflammatory focus and not being released into the lymph during the period of study or migrating from the inflammatory focus by a route other than in the effluent lymph. The only functional analysis carried out on the cellular lymphatic effluent has been the phagocytosis of sensitised sheep red blood cells (with complement). The output of the phagocytic cells is increased after intestinal anastomosis.

The intense tartrate stable acid phosphatase staining of the non-lymphocytic, non-phagocytic non-specific esterase positive cells helps to differentiate this cell from the remaining cell types in the effluent lymph. It is interesting to note that the acid phosphatase isoenzyme in the reticulum cells of leukaemic reticuloendotheliosis had similar staining characteristics and was identified as isoenzyme $5 .{ }^{16}$

ROLE OF MESENTERIC LYMPH GLANDS IN LOCALISED ACUTE INFLAMMATION OF GASTROINTESTINAL TRACT

The lymphatic effluent from the gastrointestinal tract passes through the mesenteric lymph glands before reaching the thoracic duct. The mesenteric lymph gland is ideally situated to exert a modifying influence on the effluent lymph.

On the first and second days after small intestinal anastomosis the total white cell output in rats lacking mesenteric lymph glands is lower than that of normal rats. The majority of the cells in the lymph are lymphocytes, so that the lymphocyte output in the thoracic duct lymph of normal rats with an intestinal anastomosis is greater on the first, second, 
and third days when compared with the MLNX rats. In addition to cells generated by mitosis in the mesenteric lymph gland, a significant proportion of the increased lymphocyte output must be due to the large number of $T$ lymphocytes which are recirculating through the post-capillary venules of the mesenteric lymph glands. ${ }^{17}$ The lymphocyte output in these normal rats is similar to that of MLNX rats on the fourth and fifth days presumably because the $T$ lymphocyte population of the rats will have been greatly depleted by the prolonged lymph drainage. The lymph afferent and efferent to the mesenteric lymph gland is known to have a different lymphocyte population, ${ }^{18} 19$ but the effect of intestinal anastomosis on these lymphocyte subpopulations has not been examined in this present study.

Changes have occurred in the polymorphonuclear lymphocyte and non-lymphocytic nonspecific esterase positive cell populations. Polymorphonuclear lymphocytes are present in the efferent lymph of the mesenteric lymph glands and their peak output is on the second day after anastomosis. However, the magnitude of the polymorphonuclear lymphocyte output is reduced by a factor of two in its passage through the mesenteric lymph glands. The output of non-lymphocytic nonspecific esterase positive cells is dramatically reduced by a factor of six on the second day. However, some non-lymphocytic non-specific esterase positive cells are present in the thoracic duct lymph of these animals in contrast with their absence from normal rats lacking any acute inflammatory source. It is not known whether the polymorphonuclear lymphocytes or non-lymphocytic non-specific esterase positive cells efferent to the mesenteric lymph gland are the same cells which were present in the afferent lymph or whether they are added to this lymph during its transit through the mesenteric lymph gland. From a histological examination of an inflamed popliteal lymph gland of rats it has been concluded that the polymorphonuclear leucocytes in the subcapsular sinus had been transported in the afferent lymph, whereas the polymorphonuclear leucocytes in the intermediary sinuses of the lymph gland can be stimulated by the intralymphatic injection of bacteria into the afferent vessels. ${ }^{15}{ }^{20} \mathrm{It}$ is possible that bacteria are conveyed to the mesenteric lymph glands from the intestinal anastomosis and cause a similar migration of polymorphonuclear leucocytes into the intermediary sinuses so that these cells efferent to the mesenteric lymph gland would not be derived from those entering in the afferent lymph. The mesenteric lymph glands would then be acting in a way analogous to peripheral lymph glands in removing bacteria from the afferent lymph. ${ }^{2122}$
ROLE OF LYMPH IN INITIATING AND

MAINTAINING INFLAMMATORY RESPONSE

Polymorphonuclear lymphocytes may restrict the extent of tissue invasion by noxious agents-for example, bacteria. Much work has been carried out on the mechanisms responsible for inducing the inflammatory response. In the present study there was no difference in the local polymorphonuclear lymphocyte infiltration of the anastomosis at five days in rats having thoracic duct drainage compared with undrained rats. Moreover, the thoracic duct cannulae in those rats having lymph drainage were inserted before carrying out the intestinal anastomosis. Thus, the agents responsible for initiating and maintaining the polymorphonuclear lymphocyte response are not transmitted to the appropriate stem cells via the thoracic duct lymph collected in these experiments. It is possible that the agents are conveyed to the more proximal parts of the thoracic duct via the peritoneal cavity and mediastinal lymphatics.

The expert technical assistance of Ms Jan Horrocks is gratefully acknowledged.

\section{References}

${ }^{1}$ Ryan GB, Majno G. Acute inflammation. Am J Pathol 1977; 86: 185-276.

${ }^{2}$ Yoffey JM, Courtice FC. Lymphatics, lymph and lymphoid tissue. London: Arnold, 1956.

${ }^{3}$ Clark ER, Clark EL, Rex RO. Observations on polymorphonuclear leukocytes in the living animal. Am J Anat 1936; 59: 123-73.

${ }^{4}$ Courtice FC, Simmonds WJ. Physiological significance of lymph drainage from the serous cavities and lungs. Physiol Rev 1954; 34: 419-48.

${ }^{5}$ MacPherson GG, Steer HW. Properties of mononuclear phagocytes derived from the small intestinal wall of rats. In: Müller-Ruchholtz W, Müller-Hermelink HK, eds. Function and structure of the immune system. New York: Plenum, 1979: 433-8.

${ }^{6}$ Tilney NL. Patterns of lymphatic drainage in the adult laboratory rat. J Anat 1971; 109: 369-83.

${ }^{7}$ Gowans JL. The recirculation of lymphocytes from blood to lymph in the rat: J Physiol (Lond) 1959; 146: 54-69.

${ }^{8}$ Crofton RW, Diesselhoff-Den Dulk MMC, Van Furth $R$. The origin, kinetics and characteristics of the kupffer cells in the normal steady state. J Exp Med 1978; 148: 1-17.

${ }^{9}$ Hancock PM, Hill MW, Johnson NW. The inflammatory response to paraffin in the peritoneal cavity of the rat. Br J Exp Pathol 1978; 59: 128-36.

${ }^{10}$ Hudack S, McMaster PD. The permeability of the wall of the lymphatic capillary. J Exp Med 1932; 56: 223-53.

${ }^{11}$ Miles AA, Miles EM. The state of lymphatic capillaries in acute inflammatory lesions. $J$ Pathol Bact 1958; 76: 21-35. 
${ }^{12} \mathrm{Paz}$ RA, Spector WG. The mononuclear-cell response to injury. J Pathol Bact 1962; 84: 85-103.

${ }^{13}$ Hurley JV, Ryan GB, Friedman A. The mononuclear response to intrapleural injection in the rat. $J$ Pathol Bact 1966; 91: 575-87.

${ }^{14}$ Van Furth R, Diesselhoff-Den Dulk MMC, Mattie H. Quantitative study on the production and kinetics of mononuclear phagocytes during an acute inflammatory reaction. J Exp Med 1973; 138: 1314-30.

${ }^{15}$ Smith RO, Wood WB. Cellular mechanisms of antibacterial defense in lymph nodes I. Pathogenesis of acute bacterial lymphadenitis. J Exp Med 1949; 90: 555-66.

${ }^{16}$ Yam LT, Li CY, Lam KW. Tartrate-resistant acid phosphatase isoenzyme in the reticulum cells of leukaemic reticuloendotheliosis. $N$ Engl J Med 1971; 284: 357-60.

${ }^{17}$ Gowans JL, Knight EJ. The route of re-circulation of lymphocytes in the rat. Proc Roy Soc, Lond B 1964; 159: $257-82$.

${ }^{18}$ Williams AF, Gowans JL. The presence of IgA on the surface of rat thoracic duct lymphocytes which contain internal IgA. J Exp Med 1975; 141: 335-45.

${ }^{19}$ Steer HW. An analysis of the lymphocyte content of rat lacteals. J Immunol 1980; 125: 1845-8.

${ }^{20}$ Smith RO, Wood WB. Cellular mechanisms of antibacterial defense in lymph nodes III. The origin and filtration effect of granulocytes in the nodal sinuses during acute bacterial lymphadenitis. J Exp Med 1949; 90: $567-76$.

${ }^{21}$ Drinker CK, Field ME, Ward HK. The filtering capacity of lymph nodes. J Exp Med 1934; 59: 393-405.

${ }^{22}$ Widdicombe JG, Hughes R, May AJ. The efficiency of filtration by the popliteal lymph node of the rabbit. BrJ Exp Pathol 1955; 36: 473-8. 